\title{
Research on Fitness Equipment Management System Based on .NET and MVC
}

\author{
Pan Jian \\ Bohai University, Jinzhou, P.R. China \\ 623033376@qq.com
}

Keywords: fitness equipment; .NET; MVC; functional design; management

\begin{abstract}
Fitness equipment is an important tool and means of physical education curriculum in colleges and universities. In order to improve the scientific, reasonable management of college fitness equipment, this paper studied fitness equipment management system based on a combination of .NET and MVC, the system implements the fitness equipment basic information to add, delete, modify, and retrieve operations as well as fitness equipment rental information management, and so on. First, the MVC mode was introduced, MVC is divided into model, view, controller of three kinds of parts; then, elaborated the MVC combined with.NET mode, and introduces the design idea, to provide users with a good and reliable, security, ease of maintenance management platform; Finally, introduced the system functional design based on the .NET and MVC.
\end{abstract}

\section{Introduction}

Fitness equipment is necessary teaching equipment for fitness classroom teaching and extracurricular PE activities, along with the university fitness teaching content have become increasingly rich and colorful; fitness equipment is showing a diverse characteristic. Type and quantity of fitness equipment is also increasing, equipment management is a very important link, in order to better increase the utilization of fitness equipment, and continue to extend the life of fitness equipment, colleges must improve the fitness equipment management level, the management level of fitness equipment is also an indicator to measure the work level of physical education in universities. How to fitness equipment for effective management and maintenance, play the best results, become an important content of college fitness work [1].

Fitness equipment management in the actual work process is a more complicated matter, because of school professional is more, at the same time have multiple physical education classes together, and in this case, using traditional equipment management methods cannot meet the modern fitness quality education requirements. While the use of computer technology to develop a set of fitness equipment management system, fitness equipment management realize the specialization, informationization and electronic, improve management efficiency and to change the traditional management methods of artificial registered in the past [2]. This intelligent equipment management system to improve the efficiency of the management of fitness equipment, reduce the waste of fitness equipment and management more intelligent, has a certain application value. In view of the present situation of college fitness equipment management, this paper studies fitness equipment management system based on a combination of .NET and MVC [3].

\section{MVC Mode}

MVC (Model View Controller) constitute the basis for many interactive systems. MVC structure is for those who need to provide multiple views of the same data applications program to design, it is to achieve a good separation of the data layer and the presentation layer. MVC is a kind of development mode, typically used in the design and analysis of distributed application systems, as well as for determining the organizational relationship between the various parts of the system. Interface design for the variability of demand, MVC mode consisting of interactive systems to break down into model, view, controller of three parts [4]. MVC mode is shown in Fig. 1. 
In MVC mode, the model is the core, is the data model of the system, but also on the system data abstraction, the system through Model for data manipulation, do not care about specific forms of data storage, while the business rules and business process of system encapsulated in this layers. View is the system provides users with interactive interface. View is responsible for accepting the user's request and to make a simple treatment, the processing of the business process to the model layer, while the processing results of the model layer is displayed to the user [5]. The controller defines the application logic of the system, receiving and forwarding the user's request, and operation commands through the view to control layer, the control according to the system logic to update the data of model definition, and the processing results select the appropriate view back to the user. In this system, Controller is responsible for receiving, intercept and process user requests, the process a variety of events. To obtain various data objects by calling the business logic components in model, the decision rendered view to the customer based on the current status and business operation results, to control the display of aspx page.

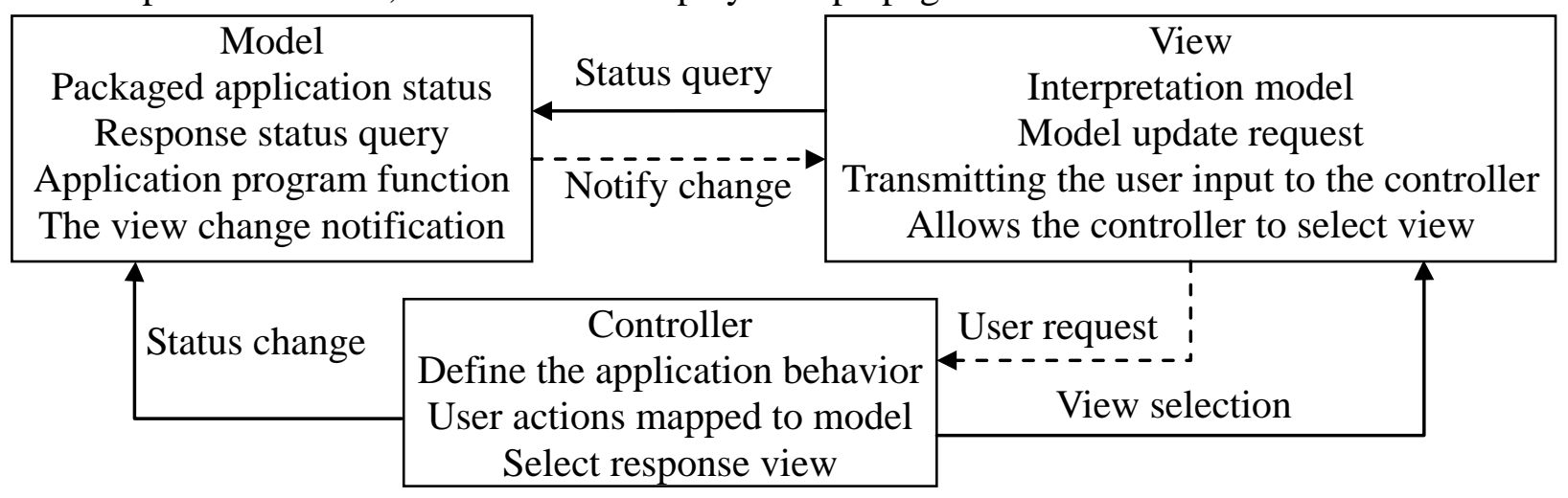

Fig. 1. MVC mode

There are many advantages of the MVC mode, which can be a model for the establishment and use of multiple simultaneous views at runtime. Changes propagation mechanism to ensure that all relevant views in a timely manner to get model data changes, so that all associated views and controllers to achieve behavioral synchronization; view and the controller can be patch, allowing replacement of the view and controller objects, and can according to the needs of a dynamic opening or closing, and even for object replacement during run time; and model portability.

\section{MVC and .NET Combination Mode}

In .NET, MVC design patterns for the three layer Web development mode is easier to achieve, in order to improve the system's versatility and can be transplanted, this article will MVC design pattern and the .NET three-tier architecture combining, the presentation layer is divided into two layer: page display layer and page interface layer, separated from the display and control; will be some changes to the MVC design pattern, the model part to be divided, independent of the data access module, take the packaging technology of class design the data access layer, business logic classes independent set model, so to achieve the physical independence of the data, realize the integration development of four layer MVC design mode and five layer Web development mode, to thoroughly solve the problem of data manipulation and data access cross together, to improve the independence between the Web layer, achieve system architecture loosely coupled, high cohesion requirements, is conducive to the system portability and cross platform, scalability function.

Specific implementation is the view expressed by the page display layer, achieved through an .aspx file, the controller is represented by the page interface layer, through .cs programming to achieve the interface control of page display and business logic (model); model section is represented by a business logic layer, achieved the part of the function by encapsulating various operations classes and data access interface class; independent data access layer alone, complete database access under the joint cooperation between Web.config and data access classes, to meet the system for database data access, update, delete, query, extract and other operating requirements [6]. Fitness equipment management system model based on a combination of .NET and MVC shown in 
Fig. 2.

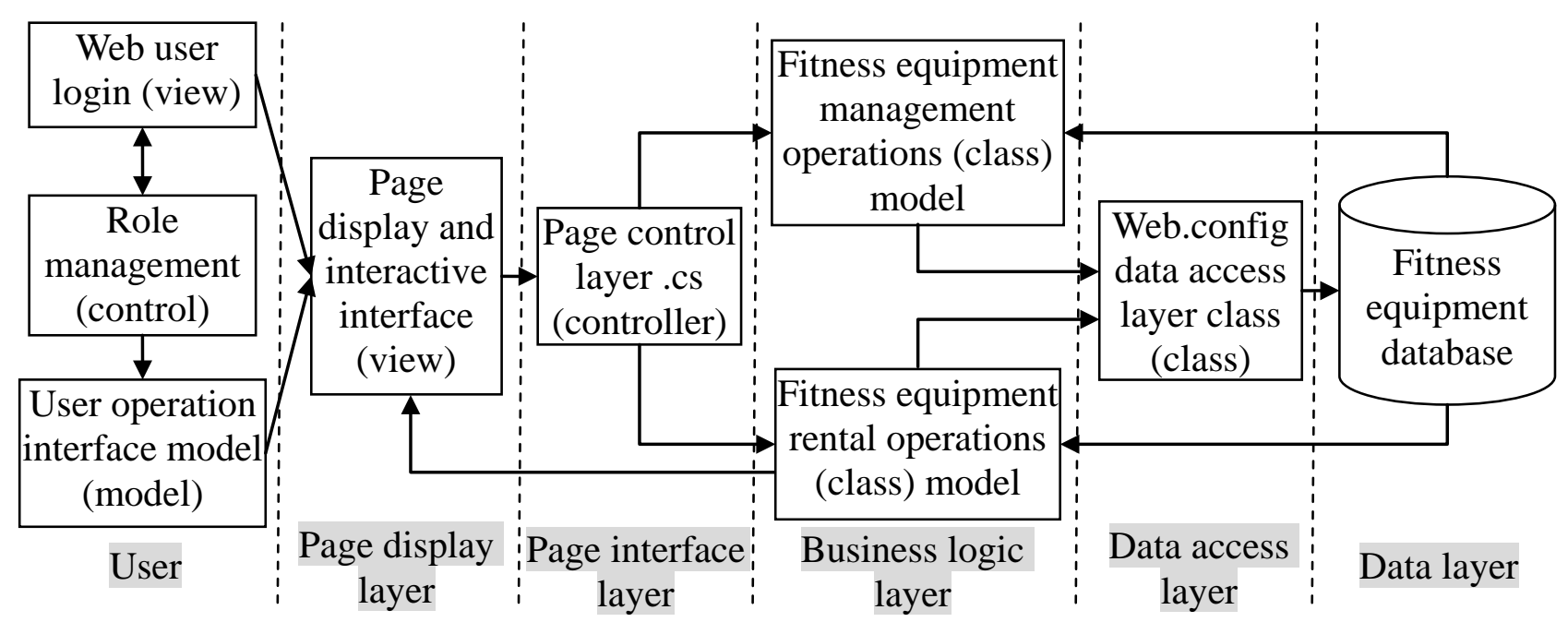

Fig. 2. Fitness equipment management system model on .NET and MVC combination

\section{Functional Design Based on .NET and MVC}

System uses the MVC design pattern, to achieve a good separation of the control logic, business logic, data logic and display, reducing code repeatability, improve the maintainability of the project. While the system is combined with the .NET framework technology, to provide users with a good reliability, security, ease of maintenance management platform.

Fitness equipment management including school fitness equipment procurement, registration allocation and inventory management and other functions, through the system function modules can understand whereabouts and dynamic of school each fitness equipment, so school fitness facilities and equipment for scientific management and distribution, can effectively control the sport equipment loss serious problem [7]. Fitness equipment management system is mainly divided into fitness equipment procurement module, the basic information module, equipment rental information module, equipment category management module, equipment enter warehouse and out of warehouse management modules, equipment maintenance module. Mainly to achieve basic information add, delete, modify, and retrieve operations. Fitness equipment lease information management, setting limits and extended the lease for compensation. Fitness equipment rental and other printed information. System functional modules are shown in Fig. 3. The main module is described as follows:

\begin{tabular}{|c|c|c|}
\hline $\begin{array}{c}\text { Fitness equipment } \\
\text { procurement module }\end{array}$ & \multicolumn{1}{|c|}{$\begin{array}{c}\text { Equipment basic } \\
\text { information module }\end{array}$} \\
\hline $\begin{array}{c}\text { Equipment enter } \\
\text { warehouse module }\end{array}$ & \multicolumn{1}{c}{$\begin{array}{c}\text { College fitness } \\
\text { equipment management } \\
\text { system }\end{array}$} & \begin{tabular}{|c|c|} 
Equipment category \\
management module
\end{tabular} \\
\hline $\begin{array}{c}\text { Equipment out of } \\
\text { warehouse module }\end{array}$ & \multicolumn{1}{|c|}{$\begin{array}{c}\text { Equipment rental } \\
\text { information module }\end{array}$} \\
\hline $\begin{array}{c}\text { Fitness equipment } \\
\text { maintenance module }\end{array}$ & $\begin{array}{c}\text { Equipment system } \\
\text { management module }\end{array}$ \\
\hline
\end{tabular}

Fig. 3. Fitness equipment management system functional modules

Procurement module, the main function is in advance of the each special classroom teachers to develop the necessary academic year and semester fitness facilities and equipment purchase plans, after summary, management personnel in accordance with plans to buy fitness equipment. Enter 
warehouse and out of warehouse modules, to achieve the entry work on equipment enter warehouse. Be entered by the form, and prevent illegal data input, ensure that the database cannot be inadvertently destroyed, and the form with automatic calculation function of the data. Achieve entry work on the equipment out of warehouse through the form. Including input, modify, delete, browse and other operations. Equipment category module, mainly is set the equipment category, determine the equipment under a particular category and specific equipment with type. Equipment maintenance modules, fitness equipment managers to fitness equipment carry out regular inspections and spot checks from time to time, take the initiative to find fitness equipment problems and maintenance, to ensure the safety of fitness equipment, thereby reducing the probability of occurrence of fitness injury.

\section{Conclusion}

Fitness equipment is an important curriculum resource of school physical education, the paper based on the idea of rational management of fitness equipment, combining the existing problems in the management of fitness equipment. The paper designed fitness equipment management system based on a combination of .NET and MVC. In order to strengthen and improve the management of college fitness equipment, to establish a sound fitness equipment management system. Improve management efficiency of college fitness equipment, accurate and timely manner to reflect the current state of college fitness equipment, to meet the requirements of an integrated information management in colleges and universities, can greatly improve the working efficiency of fitness equipment managers, reduce labor intensity of managers [8]. Strengthen the fitness equipment maintenance. Improve the quality of colleges' physical education, to ensure proper implementation of fitness curriculum. Its reasonable use on physical education curriculum will play a positive and promoting role, is an important material guarantee to improve school fitness curriculum and school fitness work smooth operations.

\section{Acknowledgement}

This work is supported by social science fund project of Liaoning province (L13BTY004).

\section{References}

[1] R. H. Zhang, "Study on The Problems and Countermeasures of College Fitness Equipment Management," Journal of Jiamusi Education Institute, vol. 30, no. 3, pp.241-242, 2013.

[2] Y. Xiong, Q. K. Xu, "Design and Implementation of Fitness Equipment Management System in Colleges and Universities," Electronic Test, vol. 21, no. 14, pp.6-8, 2014.

[3] J. D. Fu, H. X. Liu, "Implementation of Fitness Equipment Management System in College," Industrial Control Computer, vol. 27, no.6, pp.138-139, 2014.

[4] E. H. Zhang, "The Research and Application of MVC Pattern in The Information Management Platform," Shenyang Ligong University, 2009.

[5] W. Zhao, Z. H. Wang, "Design and Optimal for CMS Based on .NET and MVC," Science Technology and Engineering, vol. 13, no.3, pp.771-775, 2013.

[6] G. N. Sun, "Design and Implementation of Training Equipment Management System Based on MVC and .NET," Computer and Digital Engineering, vol. 41, no.10, pp.1632-1635, 2013.

[7] Y. Chen, "Design and Realization of Information Management System of the College Fitness Based on UM L," Fitness Forum, vol. 2, no. 3, pp.9-11, 2010.

[8] S. M. Lei, "Discussion on College Fitness Equipment Management," Bulletin of Sport Science and Technology, vol. 10, no. 11, pp.87-88, 2012. 